\title{
SUSTAINABLE OUTSOURCING DECISIONS, COMPETITIVE CAPABILITIES AND BUSINESS PERFORMANCE OF MALAYSIAN MANUFACTURING SMES: A CONFIRMATORY FACTOR ANALYSIS APPROACH
}

\author{
SITI NUR ‘ATIKAH ZULKIFFLI* AND SITI FALINDAH PADLEE \\ Faculty of Business, Economics and Social Development, Universiti Malaysia Terengganu, 21030 Kuala Nerus, Terengganu, \\ Malaysia.
}

*Corresponding author: siti.falindah@umt.edu.my

Submitted final draft: 11 May 2020 Accepted: 13 June 2020

http://doi.org/10.46754/jssm.2021.01.014

\begin{abstract}
The role of outsourcing in attaining competitive advantage and improving business performance has been widely discussed. Due to growing awareness of the importance of environmental and social responsibility issues, outsourcing firms see these issues as a strength that can be used to become more sustainable in the face of global competition. Therefore, based on an extensive literature review, a model consisting of six constructs (reducing operating costs, improving company focus, access to worldclass capabilities, unavailability of internal resources, competitive capabilities, and business performance) was developed to discover ways to push outsourcing firms to support sustainability efforts. Utilising the first-order confirmatory factor analysis (CFA) approach, a final 29-item survey covering six measurement constructs was developed and verified. The convergent validity of the constructs was also validated. The results provided an adequate fit to the Malaysian manufacturing SME data. The findings also highlighted some theoretical and methodological issues in relation to the application of the validated constructs in future work.
\end{abstract}

Keywords: Sustainability, Outsource, Competitive Advantage, Performance, Small and Medium-sized Enterprises, CFA AMOS.

\section{Introduction}

Sustainability seems to play an ever more important role in many firms today, therefore, organisations, whether large, medium, or small, need to focus on maintaining their existencein the business environment by producing useful outputs and achieving strategic goals. Toreflect a change in business environment, firms currently place more emphasis on integrating the sustainability efforts into their business activities.

These firms are changing their business strategy to provide extra services as an added value. It is also because business competition is going through a period of uncertainty due to several evolving global environmental factors, firms have recognised that there is a need to find a range of ways to remain competitive. However, when it comes to maintaining high competitiveness in international markets, firms tend to find it extremely difficult to translate planning into practice on their own. The involvement of other firms through the outsourcing of certain activities seems to be one of the most useful strategic tools for leveraging globally dispersed resources because it provides several advantages over doing it alone, suchas cost-savings and increased capabilities. By adopting this approach, firms can focus on their core competencies and externalise other activities to the experts.

Recently, the decision on whether to externalise activities has become an important consideration in organisational strategy-making. This is largely due to the pressure being exerted by shareholders on top management to achieve strategic goals (Antelo \& Bru, 2010). It can also be seen as indicative of a growing appreciation of the benefits of closer collaboration between firms and suppliers. Firms seek to create a greater competitive advantage in order to succeed in the marketplace (Derindag \& Canakci, 2019; Porter \& Kramer, 2019). It is important that such firms 
focus on core competencies, which leads some firms to select outsourcing as an option in order to gain access to high skills, to reduce costs, gain flexibility, and improve performance (Beaumont \& Sohal, 2004; Doran et al., 2019). In essence, firms need to make a well-informed decision about the best outsourcing options for them because the correct decision will result in the strengthening of their internal resources. For that reason, it is important for them to have the best strategic fit between stakeholders in the circle and also to expand their requisite capabilities (Bustinza et al., 2010; Ehie \& Muogboh, 2016).

However, some firms are facing environmental pressures in the market, which is causing them to make changes to their activities. For example, firms are being encouraged to apply the concept of sustainability to maintain an excellent reputation as a firm that fosters the spirit of high social responsibility in society. Therefore, it is necessary to consider the issue of sustainability in outsourcing decisions in order to achieve competitive advantage, particularly in respect of manufacturing activities.

These are the reasons why Malaysian manufacturing SMEs need to carefully consider their decisions regarding the outsourcing of activities in order to enhance their ability to sustain a presence in the market, which may also lead to an improvement in their business performance.

\section{Overview of Malaysian Manufacturing SMEs}

Small and medium-sized enterprises constitute the backbone of the Malaysian economy and are the engine that drives domestic growth. They are expected to have a competitive edge, technologybased operations, and to be innovative so that they can continually contribute to both the domestic and international economy. Currently, Malaysian SMEs account for more than 90 percent of the total manufacturing establishments in Malaysia (SME Corp, 2016; NSDC, 2016). In Malaysia, many industries consider it more appropriate to outsource activities that are more labour-intensive to external vendors. Most manufacturing SMEs in the country are mainly motivated to outsource in peak periods in order to achieve cost-savings, access talent, improve quality, focus on core business, and enhance capability (Halim et al., 2012; Sonfield, 2014).

In Malaysia, the manufacturing sector is currently facing problems of low productivity, pervasive of low value in a labour-intensive industry, lack of innovation and competitiveness, and weak enablers (EPU, 2015). These problems are commonly encountered by small and medium-sized enterprises (SMEs), particularly product manufacturers that are operating under a wide range of deficiencies because they are facing pressure to become 'greener' or more environmentally friendly. These smaller companies face more challenges than their larger competitors when it comes to green outsourcing because they are often constrained by scarce financial, managerial, and technological resources (Holton \& Dastmalchi, 2008; AlcaldeHeras et al., 2019). These constraints may result in low productivity and less competitiveness (Yaacob \& Tuan Hassan, 2014; Mohsenzadeh \& Ahmadian, 2016). It is also very difficult to find an SME that has extensive experience in dealing with substituting hazardous substances, designing and using eco-environmental products, saving energy, and reducing emissions.

Since independence in 1957, Malaysia has achieved remarkable success in developingits manufacturing sector and the economyas a whole. In fact, the contribution of the manufacturing sector to Malaysia's gross domestic product (GDP) increased from 8.6 percent in 1960 to 32.2 percent in 2005, while the share of manufactured goods as a proportion of total trade increased from about 25 percent in the early 1980s to around 80 percent in 2012 (Chang, 2012). Moreover, in 2014, the sector contributed a total of RM 205,200 million to GDP which was higher than the combined contribution of other sectors.

Given the importance of the manufacturing sector, and particularly the SMEs in thissector, to the Malaysian economy, this study focuses on developing a measurement model for understanding and guiding the green 
or sustainable outsourcing decisions of Malaysian manufacturing SMEs. The proposed measurement model consists of six constructs. Four of the constructs (reducing operating costs, improving company focus, access to world-class capabilities, and unavailability of internal resources) may help these firms to sustain themselves in the market. The other two constructs (competitive capabilities and business performance) are included in the model in order to identify the relative strengths of these firms as compared to those of their competitors in the target market.

The key items for these six constructs are identified through an extensive literaturereview. Then the validity and reliability of the measurement model are assessed and first-order confirmatory factor analysis (CFA) is performed using AMOS 20 to determine the fitness of the model. The first-order CFA approach is adopted as it may significantly contributeto clearly identifying the strengths of the constructs and consequently provide significant data on the effects of sustainable outsourcing and competitive capabilities on the business performance of Malaysian manufacturing SMEs.

\section{Resource-Based View (RBV) Theory}

Today, resource-based view (RBV) plays a significant role to achieve and to sustain a firm's competitive advantage in complex environments. The adoption of the RBV facilitates the building of the core competencies of a firm asit enables the firm to identify activities that can be performed internally or done externally via outsourcing (Zulkiffli et al., 2017). RBV theory can be utilised as a framework should SMEs wish to focus on external rather than in-house resources in order to remain competitive or to achieve a sustainable competitive edge. Through $\mathrm{RBV}$, firms are able to develop their unique resources, to expand its internal boundaries, to create and to sustain a competitive advantage. In practice, the outsourcing decision is an example of adopting a RBV perspective, particularly when firms facing the internal and external pressures to achieve a sustainable competitive advantage (Anderson \& Swaminathan, 2011; Wang \& Chen, 2016).

\section{Outsourcing Decisions and Sustainability}

Outsourcing has become a favoured strategic management approach in the current competitive business environment. It provides an advantage to companies as that they do not have to bear the burden of financing certain business operations over the long term. Outsourcing is a routine management activity that a firm may decideto pursue in order to transfer some of their operations to a third-party service provideror outsourcing company. Outsourcing assists firms to achieve competitive advantage by helping them to remain focused on their core competencies.

Nowadays, many firms are looking into strengthening their core competencies, saving on costs, and becoming more effective in their operations. There are also other firms that wish to focus on their core business, yet continue outsourcing their non-essentials and other critical functions simultaneously (Charles \& Edgar, 2019; Hanafizadeh \& Ravasan, 2018).

However, the success of an outsourcing strategy is never guaranteed. There are a number of reasons why firms need to consider the sustainability of outsourcing in order to make the best outsourcing decisions as it is: (i) new and relevant, (ii) driven by consumer concerns and employee expectations, (iii) important to the firm's brand reputation, and (iv) related to the government aspirations on sustainable capability. The result of a survey by Babin and Nicholson (2012) showed that 30 percent of the firms often consider the sustainability abilityof the provider when making an outsourcing decision, thus confirming that the issue of sustainability is important in outsourcing activities. The sustainable outsourcing will improve collaborative sustainability effort through better communication and trust effort of two parties - firms and outsourcing providers.

Even though outsourcing is not a new phenomenon, its strategic utilisation may lead to the acquisition and leveraging of superior 
resources. Research also shows that sustainable outsourcing has become a significant consideration in today's business environment as reflected in the high level of investment and the active involvement of top managementin this relatively new strategic paradigm (Alaghehband et al., 2011; Jain \& Natarajan, 2011, Hanafizadeh \& Ravasan, 2018). The world of outsourcing nowadays is to focus on who can bring sustainability improvements and leading global best practices to the relationship between firms and service providers. The consideration on a sustainable outsourcing decision shouldalso include economic benefits as well as other associated factors. Therefore, four outsourcing decision factors that are assumed to affect business sustainability are discussed. These factors are considered to be the top influencing factors by the Outsourcing Institute Executive Survey (2006), namely, reducing operating costs, improving company focus, access to world-class capabilities, and unavailability of internal resources.

\section{Reducing Operating Costs}

The issue of sustainability is greatly dependent on how firms may significantly manage their operational and transportation costs. Outsourcing also has the potential to reduce capital investment and some of the monies thus saved canbe transferred to other business activitiesin order to increase revenue. In addition, outsourcing can provide companies with access to complementary resources of higher quality and lower cost than in-house resources (Islam \& Sobhani, 2008; Paek et al., 2019).

Therefore, firms should pay greater attention on current sustainability issues, such as waste management practice and carbon emissions. Firms need to consider either to outsource products from domestic or international markets by considering that both markets may affect the operating costs in terms of transportation distances and unsustainable practices at low-cost destinations (Sardar et al. 2016). Yet, international markets seem to provide lowcost outsourcing as it's comparatively more cost savings than domestic markets. The quality efforts and productivity level must also be enhanced to sustain cost-savings and strengthen firms' core competencies (Porter \& Kramer, 2019; Suleman \& Ogbette, 2019).

\section{Improving Company Focus}

Sustainable outsourcing also contributes to improving the focus of organisations. It can be seen as a management philosophy that helps organisations to achieve world- class status. By integrating sustainable outsourcing decisions into business focus, firms are able to confront any challenges and re-design their business process (Siebenhüner \& Arnold, 2007). Radically changing the orientation of the firms to focus on sustainability will shift both management and employees' mindsets, which in turn may change the fundamental value of the firm (Cramer, 2005; Waddock $\&$ McIntosh, 2009), and the implementation of recent sustainable business strategies. These efforts may improve company focus, and may have the potential to yield significant benefit to the firms entirely. It also can allow organisations to focus on their core business (Yeboah, 2013; Sridarran \& Fernando, 2016) and enables firms to accelerate their growth and success through concentrating their investment on areas that offer the greatest sustainable competitive advantage (Mishra et al., 2018; Sandhu et al., 2018).

\section{Access to World-Class Capabilities}

As the world increasingly advocates the sharing of resources as part of the drive to maintain a sustainable economy, green outsourcing can become part of a company's strategic plan. Today, firms are using outsourcing to improve access to global talent and new technology capabilities. This access can indirectly enhance firms' 
ability through efficient and sustainable outsourcing activities.

Therefore, outsourcing providers can build sustainable competitive advantage and generate highest value by offering access to world-class capabilities to particular firms. It can be achieved by considering sustainability factors in their business functions, such as shorter lead times, shorter follow-up, employing professional talents in the required fields and providing and offering client firms the opportunity to learn and use the latest and sophisticated green technology. World-class capabilities are often outsourced from third-party providers by creating enduring partnershipsas many firms do not possess these capabilities themselves (Bajec \& Jakomin, 2010; Thomson \& Lawyer, 2018).

\section{Unavailability of Internal Resources}

Sustainable outsourcing can be considered the best method to adopt in this era of rapidly evolving technologies. Due to the short life cycle of products, manufacturing firms usually try to reduce expenditure while maintaining quality. Most manufacturing companies outsource some of their functions due to a lack of internal resources. By outsourcing non-core functions such as green advertising and promotions, manufacturing companies may create extra capacity and flexibility to support their core business activities. In addition, other internal resources can also be outsourced to a third-party provider so that the provider can sustain to run the business operations as well (Sinkovics et al., 2018; Chae et al., 2019). This implies that these firms need to focus more on what they can do best and less on the business processes that affect their business performance indirectly. By taking such an approach, those SMEs in Malaysia that are lacking in resources can start to invest in new technologies and equipment (Ho et al., 2016) in order to sustain their business' competitive advantage.

\section{Competitive Capabilities}

As SMEs are confronted with higher levels of complexity and uncertainty, it is significant for the firms to adjust their capabilities to cope with environmental change for achieving sustainable competitive advantages.

Competitiveness basically arises from the value or benefits created for buyers and such benefits are more costly to generate than the initial cost involved in creating a product or service (Isnuwardiati \& Sugito, 2017). The competitive capabilities that are required to create value or benefits are changing rapidly and unpredictably in today's business environment and have therefore become a main area of concern for many firms. The effectiveness of a firm's competitive capabilities can be seen where customer value has been enhanced or the relative cost of a product has been reduced and, at the same time, revenue, market share, and profit have also been simultaneously increased. Hence, it can be said that enhanced competitive capabilities generally improve business performance (Hutton \& Eldridge, 2019). Indeed, competitive capabilities have been foundto have a more prominent effect in terms of improving business performance as compared to other factors (Özdemir \& Aslan, 2011).

Firms may utilise competitive capabilities by providing a product or service that meets customer's expectations. Scholars argued that sustainable (or green) practices are highly associated with competitiveness. These practices can lead to vast savings in all types of resources, less downtime, better utilisation of by-products, safer workplace conditions, reductions in operations and product handling costs, higher product quality, and higher product resale and scrap value (Porter \& van der Linde, 1995). Therefore, in these unpredictable business environments, SMEs are recommended to continuously apply sustainable practices that includes both external and internal capabilities in order to enhance their competitiveness.

By utilising sustainable outsourcing decision as the best option, SMEs may exploit 
lower-priced or more advanced green resources with greater efficiency, simultaneously. Hence, it is hypothesised by this study that sustainable outsourcing decisions may play a key role in bolstering the competitiveness of firms as they can improve their competitive capabilities by leveraging their resources which can then be configured into routine daily operations.

\section{Business Performance}

Sustainability has long been recognised as a ubiquitous phenomenon underlying the functions and performance of firms. Those firms, including SMEs, are competing on the strength and efficacy of their sustainability business practices. These practices contribute to their firms in any ways. Therefore, this study focuses to those SMEs that consider sustainable outsourcing decisions as one of these practices. Sustainable outsourcing decisions have a significant impact on both the short- and long-term performance of a firm. The outsourcing of both the peripheral and near-core tasks has the potential to positively influence a firm's financial and non-financial performance (Jane et al., 2018). However, when it involves contracting-out a business process (or service) such as payroll service processing, this type of outsourcing may have a negative impact in the short term yet lead to a positive and significant impact on the firm's sustainability in the long run (Gorzig \& Stephan, 2002; Agburu et al., 2017).

Business performance can be sustained through the harmonisation of financial, operational, and environmental purposes in the delivery of fundamental business actions in order to maximise value. It is the performance of a corporation in all dimensions as well asfor all drivers of firms' sustainability practices (Sebhatu, 2008). The consideration of this business performance plays a key role in the sustainability practices of SMEs (Kot, 2018).

To assess the impact of sustainable outsourcing decisions towards firms' business performance, this study analyses three aspects of business performance, namely, financial performance, operational performance and environmental performance. Being aware of hazardous impacts on the environment and firms, these three aspects are significant to ensure that the transferring of some of the business operations to a third-party, service provider or outsourcing company meet sustainability requirements. Therefore, it is needed for SMEs to develop good sustainable business practices, which will automatically lead to high performance, because it also reduces enterprise risk (Hameed et al. 2017).

\section{Research Methodology}

A total of 60 items were generated from the literature (see Table 1) for inclusion in the questionnaire that was used to collect the empirical data. The questionnaire employed a five-point Likert scale ranging from $1=$ strongly disagree to $5=$ strongly agree in order to measure the four sustainable outsourcing decision constructs and the competitive capabilities construct. It also contained a five-point Likert scale ranging from $1=$ poor performance to 5 = exceptional performance to measure the business performance construct. To reduce the number of uninformed responses, a neutral response option was included for all the items as it assures the respondents that they do not need to feel compelled to answer every questionnaire item (Wilcox, 1994). The questionnaire was designed by adapting those used in previous studies (namely, Akbari, 2013; Mahmood \& Hanafi, 2013) to fit to the sustainability focus of this study. The questionnaire was assessed by experts who confirmed its validity.

For the study sample, a total of 461 manufacturing SMEs (with 5 to 200 employees) were randomly selected from the Federation of Malaysian Manufacturers directory. As these companies were located in geographically dispersed locations, a proportionate stratified random sampling based on regions was conducted by calculating a similar percentage of companies for all regions. A copy of the questionnaire was sent to the selected companies together with a pre-paid return envelope and a cover letter addressed to the company director 
or manager. The initial letter was followed by two reminder letters.

A total of 170 completed questionnaires were received from the participating companies. This represented a 36.88 percent response rate. However, the useable response rate was 34.71 percent (160 SMEs).

\section{Data Analysis and Discussion}

The data analysis was conducted by using the first-order CFA approach in AMOS software because it is the best-known statistical procedure for testing actor structures (Schumacker \& Lomax, 1996; Byrne, 2010). CFA was used to test the measurement model and to examine whether the data set fit the measurement structure. In this study, CFA was conducted based on six constructs - reducing operating costs, improving company focus, access to world-class capabilities, unavailability of internal resources, competitive capabilities, and business performance.

This study implemented a three-step process. First, the presence of outliers was assessed by the square Mahalanobis distance $\left(D^{2}\right)$ and the normal distribution of data was confirmed by skewness and kurtosis tests. Then, the goodness-of-fit of each model was assessed by employing a variety of commonly used fit indices. All 60 items were then generated and the model fitness was assessed and subjected to re-specification. The CFA approach that was used to assess the initial measurement model of sustainable outsourcing decisions (which included reducing operating costs, improving company focus, access to world-class capabilities, and unavailability of internal resources), competitive capabilities, and business performance was adapted because this study sought to examine the existence of single constructor trait underlying a set of measures and a set of items forming an instrument that all measured one thing in common.

The first fit measure that was assessed was the chi-square $\left(x^{2}\right)$ statistic. Barret (2007), Hair et al. (2010), Byrne (2010), and Pallant (2010) state that the $x^{2}$ statistic is the traditional measure for evaluating overall model fit in covariance structure models and it assesses the magnitude of discrepancy between the sample and fitted covariance. In this regard, a good model fitwould show a significant result of $p>0.05$. The $x^{2}$ statistics is often referred to as either a goodnessof-fit or badness-of-fit measure, where a large $x^{2}$ value corresponds to a bad fit and a small $x^{2}$ value corresponds to a good fit. The degree of freedom $(d f)$ serves as a standard by which to assess whether $x^{2}$ is small or large. Also, in line with Byrne (2010) and Hair et al. (2010), other model fits indices such as goodness of fit index (GFI), adjusted goodness of fit index (AGFI), Tucker Lewis index (TLI), normed chi-square $(\mathrm{CMIN} / d f)$, probability $(p)$, comparative fit index (CFI), root-mean square error approximation (RMSEA), and standardised root mean square residual (SRMR) were also employed to assess the goodness of fit of the measurement model.

Table 1 shows the initial model fit indices for all of the constructs. From the results itcan be seen that the original model needed to be re-specified in order for it to meet the unidimensionality requirement and to fit better with the sample data.

Consequently, 31 items were eliminated based on the examination of the fit indices and on two model diagnostics (standardised residuals and modification indices) (Byrne, 2010; Hair et al., 2010). The fit of the modified first-order CFA model, which consisted of 29 items, is shown in Table 2. The re-specified model fits the sample data better because $x^{2}, x^{2} / d f$, $p$, GFI, AGFI, TLI, CFI. RMSEA, and SRMR were in line with the suggested statistical values (Byrne, 2010).

Table 3 shows that the regression weights of all the variables had high factorial validity $(\lambda$

$\geq 50$ ), where the loading onto their respective factors ranged between .656 and .935. The majority of the indicators were statistically significant ( $\lambda \geq .70)$; ICF8, UIR5, and UIR7 were considered to have a .70 factor loading after rounding to two decimal places. These results confirmed that no construct was threatened by other indicators nor did the factor loading and critical ratio values indicate any threat to the 
Table 1: Initial goodness-of-fit indices for first-order CFA of each construct

\begin{tabular}{lcllllll}
\hline $\begin{array}{c}\text { Goodness- } \\
\text { of-Fit } \\
\text { Statistics }\end{array}$ & $\begin{array}{c}\text { Suggested } \\
\text { Statistical } \\
\text { Value }\end{array}$ & ROC & ICF & AWCC & UAIR & CC & BP \\
\hline$x^{2}$ & - & 174.122 & 153.182 & 266.341 & 213.815 & 224.225 & 282.870 \\
\hline$d f$ & - & 35 & 35 & 35 & 35 & 35 & 35 \\
\hline$x^{2} / d f$ & $\leq 3.00$ & 4.975 & 4.377 & 7.610 & 6.109 & 6.406 & 80.82 \\
\hline$P$ & $\geq 0.05$ & 0.000 & 0.000 & 0.000 & 0.000 & 0.000 & 0.000 \\
\hline GFI & $\geq 0.90$ & 0.771 & 0.798 & 0.068 & 0.744 & 0.729 & 0.613 \\
\hline AGFI & $\geq 0.80$ & 0.640 & 0.682 & 0.492 & 0.598 & 0.574 & 0.392 \\
\hline TLI & $\geq 0.90$ & 0.814 & 0.753 & 0.651 & 0.713 & 0.810 & 0.759 \\
\hline CFI & $\geq 0.90$ & 0.855 & 0.808 & 0.729 & 0.776 & 0.852 & 0.812 \\
\hline RMSEA & $\leq 0.08$ & 0.178 & 0.164 & 0.230 & 0.202 & 0.208 & 0.238 \\
\hline SRMR & $\leq 0.05$ & 0.063 & 0.090 & 0.115 & 0.084 & 0.059 & 0.072 \\
\hline
\end{tabular}

ROC = Reducing Operating Costs, ICF = Improving Company Focus, AWCC = Access to World Class Capabilities, UAIR = Unavailability of Internal Resources, $C C=$ Competitive Capabilities, BP $=B$ Business Performance

Table 2: Goodness-of-fit indices for first-order CFA of each construct (after modification)

\begin{tabular}{lccccccc}
\hline $\begin{array}{c}\text { Goodness-of-Fit } \\
\text { Statistics }\end{array}$ & $\begin{array}{c}\text { Suggested } \\
\text { Statistical } \\
\text { Value }\end{array}$ & ROC & ICF & AWCC & UAIR & CC & BP \\
\hline$x^{2}$ & - & 2.607 & 1.565 & 6.032 & 3.379 & 2.961 & 6.755 \\
\hline$d f$ & - & 5 & 2 & 5 & 5 & 5 & 5 \\
\hline$x^{2} / d f$ & $\leq 3.00$ & 0.521 & 0.783 & 1.206 & 0.676 & 0.592 & 1.351 \\
\hline$P$ & $\geq 0.05$ & 0.760 & 0.457 & 0.303 & 0.642 & 0.706 & 0.239 \\
\hline GFI & $\geq 0.90$ & 0.991 & 0.994 & 0.981 & 0.989 & 0.990 & 0.980 \\
\hline AGFI & $\geq 0.80$ & 0.974 & 0.970 & 0.942 & 0.968 & 0.971 & 0.940 \\
\hline TLI & $\geq 0.90$ & 1.000 & 1.000 & 0.994 & 1.000 & 1.000 & 0.993 \\
\hline CFI & $\geq 0.90$ & 1.000 & 1.000 & 0.997 & 1.000 & 1.000 & 0.997 \\
\hline RMSEA & $\leq 0.08$ & 0.000 & 0.000 & 0.041 & 0.000 & 0.000 & 0.053 \\
\hline SRMR & $\leq 0.05$ & 0.015 & 0.014 & 0.020 & 0.021 & 0.010 & 0.016 \\
\hline
\end{tabular}

Note: $R O C=$ Reducing Operating Costs, ICF = Improving Company Focus, AWCC = Access to World-Class Capabilities, UAIR = Unavailability of Internal Resources, $C C=$ Competitive Capabilities, $B P=$ Business Performance

model fit as the majority of the loadings were acceptable based on the recommended values (Byrne, 2010) and all of the critical ratio values were above 1.96 ( $p<.001)$ (Byrne, 2010). The variables also had high internal consistency $(\alpha \geq .70)$, with values ranging between 0.852 and 0.941 . Also, the squared multiple correlation values for the 29 indicators showed that most of the indicators had good item reliability $\left(r^{2} \geq .50\right)$, including indicators ROC3, ICF8, UIR5 and UIR7 (after rounding to two decimal places). The convergent validity of the constructs was also confirmed as shown by the values for composite reliability $(\mathrm{CR})$ and average variance extracted (AVE) for each construct. 
Table 3: Measurement model for each construct (after modification)

\begin{tabular}{|c|c|c|c|c|c|}
\hline Items & $(\lambda)$ & $\left(r^{2}\right)$ & $(\alpha)$ & (CR) & $(\mathrm{AVE})$ \\
\hline Reducing Operating Costs (ROC) & & & 0.888 & 0.889 & 0.617 \\
\hline $\begin{array}{l}\text { ROC3: Reducing costs of water and energy usage in } \\
\text { production activities }\end{array}$ & 0.706 & 0.499 & & & \\
\hline $\begin{array}{l}\text { ROC6: Reducing reject rates for the company's } \\
\text { products }\end{array}$ & 0.742 & 0.550 & & & \\
\hline ROC7: Reducing unnecessary product/service costs & 0.820 & 0.673 & & & \\
\hline ROC8: Reducing unnecessary processing costs & 0.884 & 0.781 & & & \\
\hline $\begin{array}{l}\text { ROC10: Reducing costs through production and } \\
\text { sales efficiency }\end{array}$ & 0.761 & 0.580 & & & \\
\hline Improving Company Focus $($ ICF $)$ & & & 0.865 & 0.871 & 0.632 \\
\hline $\begin{array}{l}\text { ICF6: Increasing the proportion of biodegradable } \\
\text { materials as a value added to the products }\end{array}$ & 0.812 & 0.659 & & & \\
\hline $\begin{array}{l}\text { ICF7: Recognising potential commercial } \\
\text { adaptations from technical innovations }\end{array}$ & 0.935 & 0.874 & & & \\
\hline ICF8: Using high-quality natural raw materials & 0.656 & 0.450 & & & \\
\hline ICF9: Developing new eco-product brands & 0.750 & 0.563 & & & \\
\hline Access to World-Class Capabilities (AWCC) & & & 0.896 & 0.902 & 0.648 \\
\hline $\begin{array}{l}\text { AWCC1: Accessing world-class leading-edge } \\
\text { technology to protect against contamination }\end{array}$ & 0.844 & 0.712 & & & \\
\hline AWCC2: Accessing holistic professionals & 0.828 & 0.685 & & & \\
\hline $\begin{array}{l}\text { AWCC3: Implementation of emerging eco- } \\
\text { technologies }\end{array}$ & 0.868 & 0.754 & & & \\
\hline $\begin{array}{l}\text { AWCC5: Using imported technologies to save } \\
\text { water and energy }\end{array}$ & 0.717 & 0.514 & & & \\
\hline $\begin{array}{l}\text { AWCC7: Using latest eco-manufacturing methods } \\
\text { to meet standards mandated by environmental law }\end{array}$ & 0.759 & 0.576 & & & \\
\hline Unavailability of Internal Resources (UAIR) & & & 0.852 & 0.854 & 0.541 \\
\hline $\begin{array}{l}\text { UIR2: Providing advanced eco-manufacturing } \\
\text { methods to reduce damage caused by waste }\end{array}$ & 0.813 & 0.660 & & & \\
\hline $\begin{array}{l}\text { UIR3: Improving capabilities of manufacturing } \\
\text { personnel in producing safe and economical } \\
\text { products }\end{array}$ & 0.727 & 0.529 & & & \\
\hline $\begin{array}{l}\text { UIR4: Assigning expert personnel in sustainability } \\
\text { to each department }\end{array}$ & 0.787 & 0.619 & & & \\
\hline $\begin{array}{l}\text { UIR5: Focusing on human resources with high } \\
\text { emotional intelligence }\end{array}$ & 0.673 & 0.456 & & & \\
\hline $\begin{array}{l}\text { UIR7: Implementing good mechanisms for } \\
\text { transferring eco-technology from research to } \\
\text { product development }\end{array}$ & 0.665 & 0.452 & & & \\
\hline Competitive Capabilities (CC) & & & 0.941 & 0.941 & 0.763 \\
\hline $\begin{array}{l}\mathrm{CC} 2 \text { : We respond to competitive moves that } \\
\text { engages in eco-activities in the marketplace }\end{array}$ & 0.850 & 0.723 & & & \\
\hline
\end{tabular}




\begin{tabular}{|c|c|c|c|c|c|}
\hline $\begin{array}{l}\text { CC3: We have the ability to track any changes in } \\
\text { customer needs and wants }\end{array}$ & 0.925 & 0.857 & & & \\
\hline $\begin{array}{l}\text { CC4: We are quick to respond to customer } \\
\text { complaints }\end{array}$ & 0.878 & 0.771 & & & \\
\hline $\begin{array}{l}\text { CC5: We compile strategic information about } \\
\text { customers and competitors }\end{array}$ & 0.861 & 0.741 & & & \\
\hline $\begin{array}{l}\text { CC8: We make the effort to implement eco-product } \\
\text { changes to overcome customer dissatisfaction with } \\
\text { existing products }\end{array}$ & 0.849 & 0.721 & & & \\
\hline Business Performance $(\mathrm{BP})$ & & & 0.923 & 0.929 & 0.725 \\
\hline BP2: Increased market share & 0.741 & 0.550 & & & \\
\hline $\begin{array}{l}\text { BP6: Lower percentage of faulty products and/or } \\
\text { sub-standard service provision }\end{array}$ & 0.794 & 0.631 & & & \\
\hline $\begin{array}{l}\text { BP7: Higher quality of products/services compared } \\
\text { to competitors }\end{array}$ & 0.949 & 0.901 & & & \\
\hline $\begin{array}{l}\text { BP9: Improved manufacturing time and customer } \\
\text { delivery times }\end{array}$ & 0.922 & 0.849 & & & \\
\hline $\begin{array}{l}\text { BP10: Improved process efficiency (faulty parts per } \\
\text { total production) }\end{array}$ & 0.834 & 0.696 & & & \\
\hline
\end{tabular}

Note: $\lambda=$ Standardised Regression Weights, $\mathrm{r} 2=$ Squared Multiple Correlations, $\alpha=$ Cronbach's Alpha, CR $=$ Composite Reliability, AVE = Average Variance Extracted

The result of CFA indicate that all the six constructs are significant variables. The analysis of this measurement model demonstrates good fit and proves that this model is valid and reliable for Malaysian manufacturing SMEs. This model was supported by Hair et al. (2010) when they mentioned that goodness of fit measure is important to look before continuing the analysis of factor in CFA. This method is carried out to determine which factors are most significant. Therefore, these six constructs are applicablefor measuring the sustainable outsourcing decisions and competitive capabilities for Malaysian manufacturing SMEs' business performance.

Outsourcing might lead to strategic disadvantage to SMEs, particularly during the economic downturn. The decision of outsourcing might bear an overwhelming increment in the operational cost. The potential risk of the loss of knowledge and expertise, also, cannot be ignored in the firm's longer perspective. Undoubtedly, outsourcing have had emerged as the most prevalent trends in global economy and economic benefits but a number of companies are also regretting on losing the control on quality of the goods and services, efficiency and price (Hirschheim, 2009; Bustinza et al., 2010; Ehie \& Muogboh, 2016).

By taking these disadvantages into account, SMEs in Malaysia need to re-structure their outsourcing decision strategy that should be able to adapt to this tendency. Therefore, SMEs need to consider the factors of sustainableoutsourcing development when discussing the decisionmaking process. This will in turn help the whole supply chain achieve strategic fit. Still, the measurement of sustainability is a difficult task due to the nature of what is being measured particularly where environmentalimpact is to be demonstrated.

Malaysian manufacturing SMEs can play a vital role in contributing to sustainable development through reducing operating costs, improving company focus, access to worldclass capabilities, and unavailability of internal resources. SMEs may create responsible business climate, provide smart philanthropy 
through intelligent alliances, better leadership and smarter management, harness and unleash human talent for designing skill, and adopt the 'green' compliance standards to gain competitive advantage. In such global context, a sustainable outsourcing decision is urgently demanded by all the SMEs nowadays.

\section{Conclusion and Recommendation}

This study makes a valuable contribution and expands the available knowledge on the measurement of sustainable outsourcing decisions, competitive capabilities and business performance. Since the issues of outsourcingand sustainability have come into prominence over the last 20 years, the importance of both outsourcing and sustainability has become increasingly recognised in the business world and the intersection of these two factors will become increasingly important both for the buyers and providers of outsourcing services in the future.

First, this paper discussed the requirements for outsourcing among manufacturing SMEs in Malaysia by illustrating the factors that may contribute to the decision to outsource within the context of the resource constraints of SMEs and the Malaysian business environment. It then presented the results of a thorough literature review that led to the identification of four constructs that influence the decision to outsource on the basis of the outsourcing provider's ability to improve the competitiveness of firms, namely, reducing operating costs, improving company focus, access to world-class capabilities, and unavailability of internal resources.

The paper also discussed the specification of measurement model for each underlying construct. The purpose of generating the measurement model by using a systematic firstorder CFA was to examine the convergent validity and reliability or internal consistencies of the items.

The paper then described and presented the results of the systematic first-order CFAthat was conducted to develop and validate the scales of the four constructs involved in outsourcing decisions as well as for two further constructs, namely, competitive capabilities and business performance. The model was assessed by examining standardised regression weights, squared multiple correlations, cronbach's alpha, and convergent validity. From the original 60 items, only 29 items could be used for further analyses as the standardised regression weights of all these items were statistically significant $(\lambda \geq .70)$. The results also provided empirical support for the structure of the sustainable outsourcing decisions, competitive capabilities and business performance scale, and confirmed that all the constructs were not threatened by other indicators, thus indicating that the model was fitted very well, and provided an adequate fit to the Malaysian manufacturing SME data.

There was also substantial support for the convergent validity of the constructs as shown by the values for the composite reliability (CR) and average variance extracted (AVE) of each construct. Therefore, the items were considered to be adequate for use in this study which focused on shedding light on the role of the sustainability orientation in outsourcing firms in order to assist them in making the sustainable decisions to improve their business performance and thus achieve competitive advantage. These items then could be used for further full structural equation modelling (SEM) analyses (Byrne, 2010).

The sustainable outsourcing decisions scale is used much less frequently than other outsourcing measures and to our knowledge, this study is perhaps the first to use CFA to test this scale. Overall, the result demonstrated that the Malaysian manufacturing SME version of the sustainable outsourcing decisions scale, which included competitive capabilities and business performance as additional constructs, presented very good psychometric characteristics.

However, the results reported herein also suggest that there is a need to add more items to the constructs in order to strengthen the means of the constructs. This may result in boosting their applicability to the Malaysian SME context 
as the majority of the items were adapted from previous studies conducted in various developed countries (Tuan \& Yoshi, 2010; Akbari, 2013). In addition, the six constructs could be subjected to further analysis at the second-order level. The analysis in this study was carried out with the aim of achieving a valid model fit for the data obtained as well as theoretical support for the developed model.

This study produced some interesting findings. However, it does have certain limitations that need to be acknowledged. As the number of respondents was small (160 useable SMEs), this may have affected the statistical accuracy and consistency of the results as the interpretation of the questionnaire content is subject to the respondents' understanding, perception, and honesty.

This paper also highlighted the role of sustainability in the decision to outsource. The results confirmed that all of the constructs had convergent validity of all constructs. However, discriminant validity was not tested. Therefore, it is suggested that future studies conduct a discriminant analysis of the constructs in order to assess the adequacy of the sample. In addition, the approach taken to the development of the structured questionnaire in this study could have led to false representation. Hence, future studies may wish to consider expanding the sampling frame in order to gain a better understanding of the outsourcing decisions in Malaysian manufacturing SMEs.

In conclusion, the aim of this study was to develop a measurement model that would encompass the factors that are relevant to sustainable outsourcing decisions, competitive capabilities, and business performance among manufacturing SMEs in Malaysia. The results of this study are reliable and can therefore be used in future studies, even though some of the theoretical and methodological work require further enrichment. Furthermore, the findings provide a strong direction for future researchers who particularly wish to focus on how capabilities emerge and diffuse in sustainable outsourcing.

\section{Acknowledgements}

This research was supported by the Ministry of Education, Malaysia under the Research Acculturation Grant Scheme (RAGS) (RAGS/1/2014/SS05/UMT//1). We would like to express our gratitude to the committee ofthe $5^{\text {th }}$ International Conference on Accounting, Business and Economics (ICABEC2018) for sharing their pearls of wisdom during the course of this research, and we thank all the "anonymous" reviewers for their insights.

\section{References}

Agburu, J. I., Anza, N. C., \& Iyortsuun, A. S. (2017). Effect of outsourcing strategies on the performance of small and medium scale enterprises (SMEs). Journal of Global Entrepreneurship Research, 7(26), 1-34.

Akbari, M. (2013). Factor Affecting Outsourcing Decisions in Iranian Industries. Dissertation, Victoria University, Melbourne.

Alaghehband, F. K., Rivard, S., Wu, S., \& Goyette, S. (2011). An assessment of the use of Transaction Cost Theory in information technology outsourcing. Journal of Strategic Information Systems, 20, 125-138.

Alcalde-Heras, H., Iturrioz-Landart, C., \& Aragon-Amonarriz, C. (2019). SME ambidexterity during economic recessions: The role of managerial externalcapabilities. Management Decision, 57(1), 21-40.

Anderson, J. C., \& Gerbing, D. W. (1988). Structural equation modeling in practice:A review and recommended two-step approach. Psychological Bulletin, 103(3), 411-423.

Antelo, M., \& Bru, L. (2010). Outsourcing or restructuring: The dynamic choice. International Journal of Production Economics, 123(1), 1-7.

Aulakh, P. S., Katobe, M., \& Teegan, H. (2000). Export strategies and performance of firms 
from emerging economies: Evidence from Brazil, Chile and Mexico. The Academy of Management Journal, 43(3), 342-361.

Babin, R., \& Nicholson, B. (2012). Why is sustainable outsourcing important? In

R. Babin and B. Nicholson, Sustainable Global Outsourcing: Achieving Social and Environmental Responsibility in Global IT and Business Process Outsourcing.London: Palgrave Macmillan UK.

Bajec, P., \& Jakomin, I. (2010). A make-or-buy decision process for outsourcing. PROMETTraffic \& Transportation, 22(4), 285-291.

Barret, P. (2007). Structural equation modeling: Adjudging model fit. Personality and Individual Differences, 42(5), 815-824.

Beaumont, N., \& Sohal, A. (2004). Outsourcing in Australia. International Journal of Operations Production Management, 24(7), 688-700.

Bogoviz, A., Berezhnoi, A., Mezhov, I., Titova, O., \& Kryukova, O. (2019), Decision making in modern business systems by the principles of outsourcing. Popkova, E., Chesnokova, A. \& Morozova,

I. (Ed.) Specifics of Decision Makingin Modern Business Systems, Emerald Publishing Limited, 141-148.

Bustinza, O. F., Arias-Aranda, D., \& GutierrezGutierrez, L. (2010). Outsourcing, competitive capabilities and performance: An empirical study in service firms. International Journal of Production Economics, 126(2), 276-288.

Byrne, B. M. (2010). Structural Equation Modeling with AMOS: Basic Concepts, Applications, and Programming. New York: Routledge Taylor \& Francis Group.

Chae, S., Lawson, B., Kull, T., \& Choi, T. (2019). To insource or outsource the sourcing? A behavioral investigation of the multi-tier sourcing decision. International Journal of Operations \& Production Management, 39(3), 385-405.
Chang, H. (2012). The manufacturing sectorand the future of Malaysia's economic development. Jurnal Pengurusan, 35, 3-12.

Charles, I., \& Edgar, D. (2019). Secured service delivery model for outsourced services in a business process outsourcing relationship. International Journal of Information and Communication Sciences, 4(1), 7-17.

Derindag, O., \& Canakci, M. (2019). Strategic human resources management in innovative firms. Anadolu Akademi Sosyal Bilimler Dergisi, 1(1), 52-77.

Doran, J., Ryan, G., Bourke, J., \& Crowley, F. (2019). In-house or outsourcing skills:How best to manage for innovation? International Journal of Innovation Management, 2050010, 1-25.

Ehie, I., \& Muogboh, M. (2016). Analysis of manufacturing strategy in developing countries: A sample survey of Nigerian manufacturers. Journal of Manufacturing Technology Management, 27(2), 234-260.

EPU (2015), Eleventh Malaysia Plan 20162020: Anchoring Growth on People, Prime Minister Department, 1-372. Malaysia: Percetakan Nasional Berhad.

EPU (2016). The Malaysian Economy in Figures. Economy Planning Unit, 1-66. Malaysia: Percetakan Nasional Berhad.

Gorzig, B., \& Stephan, A. (2002). Outsourcing and firm level performance. German Institute for Economic Research, 1-23.

Hair, J. F., William, C. B., Barry, J. B., \& Rolph, E. A. (2010). Multivariate Data Analysis, 7th Edition. New Jersey: Pearson.

Halim, H. A., Ahmad, N. H. \& Ramayah, T. (2012). Probing into the issues of outsourcing among SMEs in Malaysia. International Conference on Statistics in Science, Business and Engineering International Conference, 10-12 September, Langkawi, Malaysia.

Hameed, W., Hashmi, F., Ali, M., \& Arif, M. (2017). Enterprise risk management (ERM) 
system: Implementation problem and role of audit effectiveness in Malaysian firms. Asian Journal of Multidisciplinary Studies, 5(11), 34-39.

Hanafizadeh, P. \& Zare Ravasan, A. (2018). An empirical analysis on outsourcing decision: The case of e-banking services. Journalof Enterprise Information Management, 31(1), 146-172.

Hirschheim, R. (2009). Offshoring and the new world order. Communications of the ACM, 52 (11), 132-135.

Ho, T. C. F., Ahmad, N. H., \& Ramayah, T. (2016). Competitive capabilities and business performance among manufacturing SMEs: Evidence from an emerging economy, Malaysia. Journal of Asia-Pacific Business, 17(1), 37-58.

Holton, J., \& Dastmalchi, B. (2008). Manufacturing outsourcing for small and mid-size companies: Ten key challenges and how to address them. Symphony Consulting, 1-12.

Hutton, S., \& Eldridge, S. (2019). Improving productivity through strategic alignment of competitive capabilities. International Journal of Productivity and Performance Management, 68(3), 644-668.

Islam, M. A., \& Sobhani, F. A. (2008). Determinants of outsourcing decision in the manufacturing industry in Bangladesh. AIUB Business Economics Working Paper Series, 23, 1-15.

Isnuwardiati, K., \& Sugito, P. (2017). Demand chain management: An effort to improve competitiveness and business performance. International Journal of Science and Research, 6(8), 983-987.

Jain, R. K., \& Natarajan, R. (2011). Factors influencing the outsourcing decisions: A study of the banking sector in India. Strategic Outsourcing: An International Journal, 4(3), 294-322.

Jane, K., Aosa, P. E., Awino, P. Z., \& Njihia, P. J. (2018). Relationship between business process outsourcing and performance of oil and gas distribution firms in Kenya. Journal of Strategic Management, 2(1), 71-86.

Javidan, M. (1998). Core competence: What does it mean in practice? Long Range Planning, 31(1), 60-71.

Kot, S. (2018). Sustainable supply chain management in small and medium enterprises. Sustainability, 10(4), 11431162.

Mahmood, R., \& Hanafi, N. (2013). Entrepreneurial orientation and business performance of women-owned small and medium enterprises in Malaysia: Competitive Advantage as a mediator. International Journal of Business and Social Science, 4(1), 82-90.

Mishra, D., Kumar, S., Sharma, R. R. K., \& Dubey, R. (2018). Outsourcing decision: Do strategy and structure really matter? Journal of Organizational Change Management, 31(1), 26-46.

Mohsenzadeh, M., \& Ahmadian, S. (2016). The mediating role of competitive strategies in the effect of firm competencies and export performance. Procedia Economics and Finance, 36(2016), 456-466.

NSDC (2016). SMEs Development Policies and Programmes. National SME Development Council, 9-10. Malaysia: Percetakan Nasional Berhad.

Outsourcing Institute (2006). Executive Survey: The Outsourcing Institute's Annual Survey of Outsourcing End Users. Retrived from http://www.outsourcing.com/.

Özdemir, A., \& Aslan, E. (2011). Supply chain integration, competition capability and business performance: A study on Turkish SMEs. Asian Journal of Business Management, 3(4), 325-33.

Pace, K. K. (2016). Outsourcing Human Resource Competencies: A Quantitative Study of their Influence on Operational Performance, Dissertation, Capella University. 
Pallant, J. (2011). A Step By Step Guide to Data Analysis using SPSS Program Survival Manual, 4th Edition. Allen \& Unwin, NSW, Australia.

Paek, B., Kim, J., Park, J. \& Lee, H. (2019). Outsourcing strategies of established firms and sustainable competitiveness: Medical device firms. Sustainability, 11(4550), 1-28.

Pinjala, S. K., Pintelon, L. \& Vereecke, A. (2006). An empirical investigation on the relationship between business and maintenance strategies. International Journal of Production Economics, 104, 214229.

Porter, M. E. \& Kramer, M. R. (2019). Creating shared value. In: Lenssen G., Smith N. (eds) Managing Sustainable Business. Springer, Dordrecht.

Porter, M. E. \& van der Linde, C. (1995). Green and competitive: Ending the stalemate. Harvard Business Review, 73(5), 120-134.

Samsudin, N., Hashim, R. \& Fuzi, S. F. S. M. (2013). Electronic government outsourcing issues in Malaysia. Journal of Outsourcing \& Organizational Information Management, 2013, 1-10.

Sandhu, M. A., Shamsuzzoha, A. \& Helo, P. (2018). Does outsourcing always work? A critical evaluation for project business success. Benchmarking: An International Journal, 25(7), 2198-2215.

Sardar, S., Lee, Y. H. \& Memon, M. S. (2016). A sustainable outsourcing strategy regarding cost, capacity flexibility, and risk in a textile supply chain. Sustainability, 8 (234): 1-19.

Schumacker, R. E. \& Lomax, R. G. (1996). A Beginner's Guide to Structural Equation Modeling, New Jersey: Lawrence Erlbaum Associates.

Sebhatu, S. P. (2008). Sustainability performance measurement for sustainable organizations: Beyond compliance and reporting. In Proceedings of the 11th QMOD Conference. Quality Management and Organizational Development Attaining Sustainability from
Organizational Excellence to Sustainable Excellence, Helsingborg, Sweden, 20-22, 75-87.

Shafiq, A., Johnson, P. F. \& Awaysheh, A. (2019). Emerging economy sourcing: Implications of supplier social practices for firm performance. International Journal of Production Economics, 218, 148-158.

Siebenhüner, B. \& Arnold, M. (2007). Organizational learning to manage sustainable development. Business Strategy and the Environment, 16, 339-353.

Sinkovics, R., Kuivalainen, O. \& Roath, A. (2018). Value co-creation in an outsourcing arrangement between manufacturers and third party logistics providers: Resource commitment, innovation and collaboration. Journal of Business \& Industrial Marketing, 33(4), 563-573.

SME Corp. (2016). Laporan Tahunan PKS 2015/2016. SME Corporation Malaysia, 1187, Malaysia: National SME Development Council.

Sonfield, M. C. (2014). Outsourcing strategies for small business: Issues, theoretical bases and guidelines. Small Business Institute Journal, 10(2), 35-43.

Sridarran, P. \& Fernando, N. G. (2016). Change management framework to enable sustainable outsourcing of facilities management services. Built Environment Project and Asset Management, 6(3), 317331.

Suleman, A. O. \& Ogbette, A. S. (2019). Human resource management: Implications of outsourcing in public organisations in Nigeria. Public Policy and Administration Research, 9(2), 27-31.

Tan, L.-P., \& Sia, G. L. T. (2001). ISO 9000: The answer for total quality management implementation: The Malaysian case. Total Quality Management, 12(2), 223-229.

Thomson, L. L. \& Lawyer, S. (2018). Third-party vendors can be a weak link: ABA Vendor 
contracting cybersecurity checklist focuses on the procurement process to strengthen security protections, Chicago, 14(3), 36-37.

Thompson, P., Okorie, C. \& Sakty, K. E. (2019). An exploratory study of the strategic use of $3 \mathrm{pls}$ for cost reduction and customer satisfaction in the oil and gas industry: Nigerian firms' experience. Journal of Supply Chain Management Research and Practice, 13(1), 27-42.

Tuan, N. P. \& Yoshi, T. (2010). Organisational capabilities, competitive advantage and performance in supporting industries in Vietnam. Asian Academy of Management Journal, 15(1), 1-21.

Wang, T.-C. \& Chen, M.-F. (2016): Research on integrating $\mathrm{RBV}$ and $\mathrm{TCE}$ to explore outsourcing decision of TMT. International Journal of Economics, Finance and Management Science, 4(6), 378-383.
Wilcox, J. B. (1994). Assessing sample representativeness in industrial surveys. Journal of Business \& Industrial Marketing, 9(2), 51-61.

Yaacob, M. R. \& Tuan Hassan, T. M. R. (2016). Senario usahawan dan keusahawanan Melayu dalam industri perabot di Malaysia. Prosiding PERKEM Ke-9, 866-874.

Yeboah, A. (2013). The relationship between outsourcing and organizational performance. European Journal of Business and Management, 5(2), 1-12.

Zulkiffli, S. N. A, Sebadak, M., Padlee, S. F. \& Yusof, J. M. (2017). Competitive capabilities of Malaysian SMEs: In the perspectives of business and public policies. 5th International Conference on Literature, Humanities, Education, Business and Corporate Social Responsibilities (LHEBC17), Pattaya, Thailand, 3-4 Ogos 2017, 4-8. 